\title{
EDUCAR A PARTIR DE DIFERENTES MODELOS DE SAÚDE: DISCUTINDO BACTÉRIAS NO ENSINO DE CIÊNCIAS
}

\author{
TEACHING FROM DIFFERENT HEALTH MODELS: DISCUSSING BACTERIA IN \\ SCIENCE EDUCATION
}

\author{
Dália Melissa Conrado ${ }^{1}$, Liziane Martins², Michelle Silva Borges ${ }^{3}$, Leila Cristina Aoyama Barbosa \\ Souza ${ }^{4}$
}

Recebido: junho/2020 Aprovado: janeiro/2021

\begin{abstract}
Resumo: Ações educacionais para a promoção de saúde são socialmente relevantes. Refletir e discutir sobre essas práticas e os fundamentos que as embasam são oportunidades para se melhorar o ensino de conteúdos relacionados à saúde e os resultados na mobilização desses conteúdos no cotidiano dos sujeitos. Os modelos de saúde influenciam nos modos e métodos de se ensinar e aprender sobre saúde. Nesse trabalho teórico, discutimos uma questão sociocientífica sobre bactérias e saúde para caracterizar dois modos de se conceber saúde e suas consequências para a educação em saúde e a formação dos cidadãos. Argumentamos que cada enfoque sobre a saúde pode ser considerado e adotado em diversos contextos educativos e para o alcance de diferentes objetivos de ensino e aprendizagem. Contudo, é importante ter clareza desses modelos, sobretudo na atuação docente. Por fim, apontamos algumas perspectivas para a melhoria da formação e da atuação de professores de ciências.
\end{abstract}

Palavras-chave: educação contextualizada, materiais de ensino, educação em saúde.

Abstract: Educational actions for health promotion are socially relevant. Reflecting and discussing these practices and the foundations that underpin them are opportunities to improve the teaching of health and the mobilization of these contents in the daily life. Health models influence ways and methods of teaching and learning about health. In this theoretical work, we discuss an example of a socio-scientific issue about bacteria and health to characterize two ways of conceiving health and its consequences for health education and citizenship. We argue that each approach to health can be considered and adopted in different educational contexts. However, it is important to have a clarification of these models in the education. Finally, we point out some perspectives for improving the formation of science teachers.

Keywords: contextualized education, teaching materials, health education.

https://orcid.org/0000-0002-7955-2515 - Doutora em Ensino, Filosofia e História das Ciências (PPGEFHC) (UFBA/UEFS) e Doutora em Ecologia (PPGECOBIO) pela Universidade Federal da Bahia (UFBA). Professora colaboradora do Programa de PósGraduação em Educação da Universidade Federal da Grande Dourados (PPGEdu/UFGD), Dourados, Mato Grosso do Sul, Brasil. Pesquisadora do INCT IN-TREE (UFBA, Salvador, Bahia, Brasil). Endereço: Rodovia Dourados-Itahum, KM 12, Unidade II, FAED. 79804970, Dourados, MS, Brasil. E-mail: profdalia@gmail.com

2 (iD) https://orcid.ora/0000-0001-8015-4656 - Doutora em Ensino, Filosofia e História das Ciência pela Universidade Federal da Bahia (UFBA), professora da Universidade do Estado da Bahia (UNEB) e da Universidade Federal do Sul da Bahia (UFSB), Teixeira de Freitas, Bahia, Brasil. Avenida Kaikan, s/n., Jardim Caraípe, 45995-000, Teixeira de Freitas, BA, Brasil). E-mail: lizianeufsb@gmail.com 3 (iD https://orcid.org/0000-0002-8152-9285 - Especialista em Embriologia Clínica pelo Instituto Valenciano de Infertilidad, Espanha (IVI-Valência, Espanha), Conselheira do Conselho Regional de Biologia (CRBio-8), Salvador, Bahia, Brasil. Endereço para correspondência: CRBIO-8. Rua Frederico de Castro Rabelo, 114 - 6o andar-Comercio, 40.015-040, Salvador, BA, Brasil. E-mail: borges.ms@gmail.com

4 (iD https://orcid.org/0000-0002-6021-3855 - Doutora em Educação Científica e Tecnológica pela Universidade Federal de Santa Catarina (UFSC), Professora da Escola Técnica Estadual de Rondonópolis/MT e Pesquisadora Associada da Universidade Federal de Rondonópolis (UFR), Rondonópolis, Mato Grosso, Brasil. Av. Bandeirantes, 5117, Vila Operária, 78720-587, Rondonópolis, MT, Brasil).E-mail: aoyama.leila@gmail.com 


\section{Introdução}

A promoção de saúde depende de diversos fatores, como políticas públicas, ação do cidadão e da educação em saúde (MARTINS, 2011; 2016; NAIDOO; WILLS, 2009). Uma vez que o ser humano percebe que não está isolado e depende, cada vez mais, de um meio socioambiental equilibrado, a educação em saúde, para suprir as demandas contemporâneas, deve promover não só o aumento do conhecimento sobre saúde, mas também a melhoria das condições do indivíduo, das sociedades e dos ambientes (CARVALHO, 2006; CARVALHO et al., 2007; MARTINS, 2011; BENCZE et al. 2019).

Os modelos de saúde influenciam concepções e práticas individuais e coletivas, com consequências para os modos e métodos de se ensinar e aprender sobre saúde (MARTINS; CASTRO, 2009; ODA, 2012; FERREIRA; DIONOR; MARTINS, 2013). Nesse contexto, podemos pensar a educação em saúde em, ao menos, dois níveis: 1) a saúde individual humana e 2) a saúde do meio natural (natureza) que influencia sociedades humanas (EWLES; SIMNETT, 2003; VALADÃO, 2004). Conforme investigações sobre a educação em saúde no Brasil, podemos perceber um predomínio sobre o enfoque da saúde individual (MARTINS; SANTOS; EL-HANI, 2012; CARVALHO et al., 2007; 2008; MARTINS; EL-HANI; CARVALHO, 2016; MARTINS et al., 2017). Um ensino com apenas esse enfoque tem consequências para as concepções e ações dos sujeitos; por exemplo, em seu modo de interagir com a sociedade e com o ambiente.

No ensino de ciências, um modo de abordar uma formação mais abrangente, para atuação individual, social e ambiental dos sujeitos, é a educação Ciência-Tecnologia-SociedadeAmbiente (CTSA). A educação na perspectiva CTSA permite problematizar o ensino de ciências e torná-lo mais atraente e contextualizado para os estudantes, por estimular mobilização de conteúdos e discussões sobre natureza da ciência, confrontando valores e ideologias da sociedade que direcionam o desenvolvimento científico e tecnológico e suas consequências socioambientais (SANTOS, 2012; MARTÍNEZ PÉREZ; PARGA LOZANO, 2013; ROSA; AULER, 2016; SARMENTO et al., 2019; RODRIGUES; VON LINSINGEN; CASSIANI, 2019). A perspectiva CTSA pode ser empregada na educação em saúde a partir de Questões Sociocientíficas (QSC), que são problemas sociais complexos transpostos para o contexto educacional, de modo a favorecer a discussão das relações entre os domínios CTSA, além de facilitar o reconhecimento das complexas relações entre indivíduo, sociedade e ambiente e estimular a promoção de uma formação contextualizada nessas relações (LEE, 2012; FENSHAM, 2012; MARTINS et al., 2016; MARTINS et al., 2017; CONRADO, 2017; MARTINS et al., 2018). Segundo os autores, uma educação em saúde mais ampla e contextualizada pode ser alcançada com a educação CTSA e o uso de QSC. Contudo, iniciativas de educação em saúde considerando os objetivos da educação CTSA, e a partir do uso de QSC, ainda são incipientes no Brasil (CONRADO; NUNES-NETO; ELHANI, 2020).

Devemos notar que os docentes envolvidos na educação em saúde influenciam outros sujeitos que atuam na saúde como um todo; desde cidadãos até profissionais e stakeholders, com consequências para as condições socioambientais de vida entre humano e natureza (CONRADO; NUNES-NETO; EL-HANI, 2020). Mesmo no contexto do ensino superior de saúde, 
Cyrino et al. (2015, p.153) apontam, em suas conclusões, um desafio para a pesquisa envolvendo educação em saúde:

[...] os dilemas da prática docente e do ensino em saúde não são meramente instrumentais: exigem que se trabalhe no sentido de criar, ampliar e diversificar modelos, técnicas, conhecimentos e práticas formativas que levem ao estabelecimento de distintas relações entre o saber pedagógico, o saber científico e o saber oriundo da experiência no e para o trabalho.

Deste modo, considerando 1) a necessidade de uma educação em saúde mais ampla, superando modelos tradicionais reducionistas e tecnicistas; 2 ) os benefícios e vantagens nos processos de ensino e aprendizagem alcançados e na formação cidadã, a partir da educação CTSA, com QSC; e 3) a relevância de estudos para buscar uma formação docente mais ampla e integrada; nesse trabalho teórico, temos como objetivo discutir uma QSC no ensino sobre bactérias e saúde sob o ponto de vista de dois grandes modelos de saúde e suas consequências para a educação em saúde, sobretudo no contexto da Educação CTSA. Para isso, descrevemos as principais características desses dois modelos de saúde e como eles podem ser abordados na discussão de uma QSC sobre bactérias e saúde.

\section{Modelos de Saúde e Educação em Saúde}

A saúde humana depende de diversos fatores, altamente relacionados, como o bem-estar físico e emocional, as relações com os outros humanos, além da interação dos indivíduos com o ambiente (LI, 2015; ZEYER; DILLON, 2014; MYERS et al., 2013; MARTINS; SANTOS; EL-HANI, 2012; MARTINS, 2016). Nos ambientes educativos, a concepção de saúde pode influenciar no modo com o qual vinculamos os conteúdos de ensino e aprendizagem. Dois modelos bem diferentes são caracterizados a seguir, sendo também relacionados com práticas pedagógicas.

\section{Modelo Biomédico}

O modelo biomédico tem como base a concepção de saúde como ausência de doença no indivíduo, com a compreensão de sujeito saudável como aquele que apresenta funcionamento normal de seu organismo, isto é, quando suas funções biológicas estão dentro da curva normal estatística para o padrão de sua idade (BOORSE, 1975; 1977).

Segundo Carvalho et al. (2008), esse modelo enfoca a identificação e o tratamento de doenças como os principais fatores para o alcance da saúde. Os fatores biológicos do organismo são os responsáveis para a saúde do indivíduo, desconsiderando-se fatores políticos, sociais, econômicos, culturais, psicológicos e ambientais como condições que influenciam a saúde (DE SALAZAR, 2007). O desenvolvimento de tecnologias para diagnóstico e tratamento de doenças, assim como o sanitarismo e a produção de antibióticos para o controle de infecções foram ações políticas predominantes deste modelo de saúde, no final do século XIX e início do século XX, que se voltavam à manutenção de características consideradas adequadas do indivíduo (CARVALHO et al., 2008).

A educação do cidadão, segundo esse modelo, é voltada para o acúmulo de conhecimentos sobre doenças e o desenvolvimento de hábitos do indivíduo, buscando manter 
um padrão de normalidade determinado pela ciência. Nesse sentido, informações são transmitidas e adquiridas para que o sujeito adote determinados comportamentos para evitar desenvolver doenças. Isso pode levar a um comportamento de transferência de responsabilidade sobre a saúde para o profissional da área médica, ao cientista e suas tecnologias (CARVALHO, 2012). Além disso, quando o foco está na doença e não na saúde, ações de remediação (ou tratamento de doenças) de profissionais de saúde podem ser prioritárias em detrimento de ações de prevenção (com autonomia para agir em si e em seu entorno) provindas do próprio sujeito, que se torna 'paciente' e, por isso, passivo no processo de manutenção da própria saúde (SEGRE; FERRAZ, 1997).

\section{Modelo Socioecológico}

Considerada uma perspectiva mais abrangente, que relaciona aspectos biológicos às influências internas ao sujeito (como nutrição e emoção) e às interações do sujeito com os outros e o ambiente (como relacionamentos com a família e a natureza). Além disso, esse modelo reconhece que ações políticas preventivas, como melhoria das condições de higiene, nutrição, saneamento e educação, são fundamentais para a promoção da saúde (CARVALHO, 2012).

A partir da década de 1980, com o surgimento de ideias relacionadas à Promoção de Saúde, houve maior investimento na capacitação do sujeito para melhor conhecer e controlar fatores que interferem na saúde; o reconhecimento e o controle sobre os determinantes modificáveis de saúde foram então considerados como bases para a promoção da saúde, incluindo as condições de vida e de trabalho, além de educação para que o sujeito pudesse assumir a responsabilidade sobre sua própria saúde (BUSS, 2000; 2005; BUSS; PELLEGRINI FILHO, 2007; NUTBEAM, 1988; 2000).

Nesse sentido, a educação em saúde aborda o desenvolvimento de habilidades e atitudes para melhorar as condições que afetam a saúde humana e para capacitar os estudantes na tomada de decisão sobre estilos de vida saudáveis, indo além da ideia de prevenção de doenças, apenas por comportamentos individuais, ao adotar também uma visão coletiva de saúde (CARVALHO, 2012). Assim, "é necessária uma abordagem mais abrangente, que explicitamente reconheça as influências sociais e ambientais na escolha de estilos vida [...]" (NUTBEAM, 2000, p. 261). Nesse caso, o foco está em educar para que o sujeito tenha ações voltadas à manutenção da homeostasia de seu organismo e do entorno, particularmente levando em conta a totalidade do sujeito como parte de um coletivo social ou de uma comunidade, imerso em um sistema complexo e interdependente, e não apenas como um indivíduo biológico isolado (GAVIDIA; TALAVERA, 2012).

Podemos considerar que esses modelos de saúde se referem a entidades e processos em diferentes níveis hierárquicos, sendo o modelo biomédico situado em um nível do organismo individual humano e o modelo socioecológico correspondente a um nível ambiental e ecossistêmico, o que inclui o nível de organismo, todavia com um enfoque mais abrangente do que o do modelo biomédico. Nesse sentido, a saúde, se considerada em diferentes enfoques, adquire significados distintos, mas complementares. Inicialmente, o termo 'saúde', para a Organização Mundial de Saúde, se referia a uma "situação de perfeito bem-estar físico, mental 
e social", sendo questionados, sobretudo, as ideias de perfeito (como se fosse possível um estado de perfeição), bem-estar (por ser uma condição subjetiva), físico, mental e social (por não haver, na prática, essa segmentação) (SEGRE; FERRAZ, 1997; BUNGE, 2012). Uma percepção mais ampla de saúde como um constante processo de construção de interações harmônicas entre organismos (e seus produtos), já altera as ideias iniciais de passividade do sujeito e de fragmentação entre indivíduo e mundo (CONRADO; NUNES-NETO; EL-HANI, 2020). A partir dessa ideia, o sujeito não transmite uma doença ou se contamina; ele transmite ou interage com um organismo (ou algum produto do organismo) que causa um estado de desequilíbrio no próprio organismo do sujeito, ocasionando a doença (BUNGE, 2012). Nesse raciocínio, o estado de desequilíbrio é influenciado pelas condições do sujeito e seu entorno. Bunge (2012, p.73) complementa com a ideia de integração entre indivíduo e entorno, ocorrendo influências mútuas entre o organismo e a enfermidade: "Não há doenças em si que se possa adquirir ou perder, descartar ou transmitir, como se fossem coisas separadas dos organismos afetados por elas" (tradução nossa). Assim, ambos os modelos de saúde são relevantes para se entender a saúde e a importância de sua manutenção: inicialmente em um nível individual e particular, mas também em um nível coletivo e geral, de interação do indivíduo consigo e com o todo (CONRADO; NUNES-NETO; EL-HANI, 2020).

Dentro da educação em saúde, os modelos biomédico e socioecológico podem determinar estratégias didáticas e objetivos de aprendizagem complementares. No ensino de ciências, é recomendável essa associação entre ambas as perspectivas, sobretudo porque ainda é predominante o modelo biomédico de saúde, com foco na doença e na responsabilização dos indivíduos e de instituições médicas e tecnológicas; sendo esta abordagem insuficiente para capacitar o estudante a ações que visem à promoção de saúde (CARVALHO, 2012; EMMEL et al., 2018), principalmente, através de práticas de saúde coletivas e políticas. Além disso, ainda é incipiente o desenvolvimento de estratégias que contextualizem as discussões e reflexões sobre saúde, principalmente em termos ambientais (FENSHAM, 2012; KYBURZ-GRABER, 2012).

\section{Uso de Questões Sociocientíficas (QSC) para discutir saúde no ensino de ciências}

As QSC são problemas sociais complexos, que podem ser adotados na estruturação de uma educação mais contextualizada para formação de indivíduos engajados e preparados para lidar com os desafios contemporâneos (RATCLIFFE; GRACE, 2003; ZEIDLER et al., 2005; HODSON, 2018). O ensino baseado em QSC, no contexto pedagógico da Educação CTSA, busca, de modo interdisciplinar, mobilizar conteúdos específicos de ciência e tecnologia contextualizados com aspectos históricos, sociais, econômicos, culturais e éticos, envolvendo principalmente a discussão de valores, controvérsias, com posicionamento crítico e tomada de decisão (CONRADO; NUNES-NETO, 2018; BENCZE et al., 2019; CONRADO; NUNES-NETO; EL-HANI, 2019). Isso significa que o estudante poderá desenvolver habilidades investigativas e argumentativas, compreender criticamente a natureza da ciência, bem como refletir sobre suas ações no cotidiano, e promover mudanças individuais e coletivas de modo socioambientalmente responsável (CONRADO, 2017), como, por exemplo, em sua atuação para promoção de saúde individual e coletiva. Deste modo, o uso de QSC é um meio para se alcançar os objetivos da 
educação CTSA e pode ser adequadamente inserido em intervenções relacionadas à educação em saúde.

Vários temas têm sido desenvolvidos no contexto da educação em saúde envolvendo relações CTSA e ensino baseado em QSC, como: transgênicos (CARVALHO et al., 2018); terapias gênicas (SILVA, 2018); medicalização da vida (SANTOS et al., 2018); hábitos alimentares (EKBORG; IDELAND; MALMBERG, 2009; MARTÍNEZ PÉREZ; VILLAMIZAR FÚQUENE, 2014); agrotóxicos (ANDRADE et al., 2016); doença de chagas (MARTINS et al., 2018); dengue e zika (MARTINS et al., 2016); poluição (SANTOS; CONRADO; NUNES-NETO, 2018). Conforme os autores, todos esses temas possuem questões controversas e estão presentes no cotidiano dos estudantes, possibilitando maior interesse e engajamento destes para a discussão, o posicionamento, a tomada de decisão e/ou o planejamento de ações sobre os impactos da QSC na sociedade. Nesse sentido, os conteúdos relacionados à temática da QSC são trabalhados numa perspectiva mais ampla e que permitem ações para gerar melhorias na realidade vivenciada pelos estudantes (BENCZE et al., 2019). Assim, com o ensino baseado em QSC, os estudantes podem integrar conhecimentos, habilidades e valores na discussão de problemas socioambientais que afetam humanos e natureza, além de mobilizar os conteúdos escolares e perceber a importância desses conteúdos para resolver problemas sociais que os afetam diretamente ou indiretamente e para sua participação como cidadão ativo e promotor de uma sociedade melhor (HODSON, 2011; 2018).

Considerando o exposto, discutiremos, a seguir, possibilidades para a abordagem do tema Resistência Bacteriana a Antibióticos como uma QSC na educação CTSA.

\section{Resistência Bacteriana a Antibióticos como QSC no ensino de ciências}

O grande aumento de bactérias resistentes a antibióticos tem preocupado instituições, governos e nações em todo o mundo (CDC, 2015; KIRBIS; KRIZMANA, 2015). Complicações sociais, como o aumento de óbitos de pessoas acometidas por bactérias resistentes já são o foco de discussões sobre principais doenças do século XXI (CDC, 2015; ADEGOKE; FALEYE; STENSTRÖM, 2018; TACCONELLI et al., 2018). Além disso, complicações ambientais, como o surgimento de bactérias resistentes a antibióticos em animais selvagens (POWER; EMERY; GILLINGS, 2013) e o uso de antibióticos em animais de criação para alimentação humana (MARSHALL; LEVY, 2011; KIRBIS; KRIZMANA, 2015) também indicam consequências para a natureza relacionadas às escolhas e ações humanas.

Nesse sentido, levando-se em conta a necessidade de se educar melhor a população sobre esse assunto, o uso indiscriminado e inadequado dos antibióticos e o surgimento da resistência bacteriana a antibióticos podem ser considerados QSC relevantes para serem abordados no ensino de ciências, sobretudo 1) como modo de perceber a importância e de ser capaz de mobilizar conteúdos aprendidos em sala de aula; 2) para o enfrentamento de tais problemas de saúde humana e ambiental, permitindo, dessa forma, maior reflexão sobre essa temática; e 3) para uma tomada de decisão mais informada (CONRADO, 2017). 
Friedrichsen et al (2016) construíram uma unidade de instrução baseada na temática em questão (resistência a antibióticos) para ser utilizada na disciplina de biologia do ensino médio. Como principais resultados obtidos, destacam que a QSC selecionada é uma questão envolvente para os alunos, que, na atividade culminante, escreveram recomendações de políticas para reduzir a propagação da resistência a antibióticos.

Em relação ao modo como as informações podem estar entrelaçadas no desenvolvimento de uma QSC, considera-se que pode haver o predomínio de C, T, S, ou A. Nesse caso, podemos dizer que há o predomínio do domínio $\mathrm{C}$, quando priorizamos a definição, a organização ou a explicação de dados científicos (por exemplo, conhecimentos científicos sobre a reprodução bacteriana ou a fisiologia do aparelho gastrintestinal humano); há o predomínio do domínio T, quando priorizamos técnicas, produtos ou artefatos tecnológicos (como, por exemplo, as tecnologias para a deteç̧ão de bactérias em um meio ou para o desenvolvimento de novos antibióticos); há o predomínio do domínio $\mathrm{S}$, quando priorizamos conhecimentos construídos pela sociedade, excluindo aqueles científicos e tecnológicos (por exemplo, as soluções apresentadas para o problema da resistência bacteriana a antibióticos, seguindo modelos de saúde diferentes); e, por fim, que há o predomínio do domínio A, quando priorizamos a explicação ou a descrição de uma situação ambiental que condiciona o ambiente ou que é uma consequência ambiental envolvida na QSC (por exemplo, quando identificamos animais contaminados por antibióticos liberados no ambiente) (SARMENTO et al., 2019; QUEIROZ; CONRADO; SILVA, 2019; CONRADO; NUNES-NETO; EL-HANI, 2020).

Uma forma de perceber relações entre os domínios CTSA é por meio de um mapa, contendo termos que representam esses elementos (CONRADO, 2017). O mapeamento, aqui mostrado na Figura 1, auxilia na visualização das complexas relações de uma QSC, indicando a contribuição de diferentes conteúdos para a compreensão de um assunto controverso.

Figura 1 - Mapeamento de alguns elementos e relações entre os domínios CTSA, associados ao tema Resistência Bacteriana a Antibióticos.

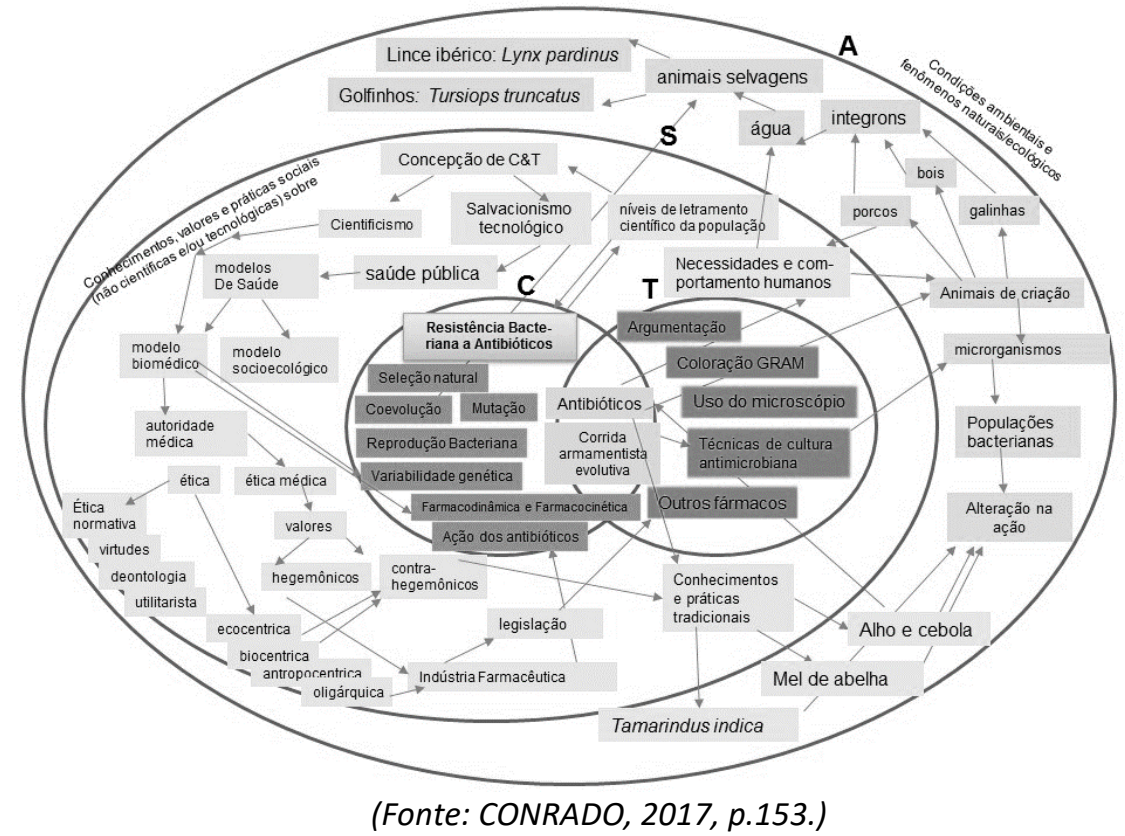

Legenda: C: conhecimentos científicos; T: técnicas e tecnologias; S: conhecimentos, valores e práticas sociais; A: condições e condicionantes ambientais 
A partir de um mapeamento dos domínios CTSA de um tema de QSC, podemos selecionar os conteúdos a serem discutidos em sala de aula, sempre considerando o nível de ensino e o tempo escolar para uma abordagem adequada deles (SARMENTO et al., 2019). Muitos desses conteúdos não possuem um domínio $\mathrm{C}, \mathrm{T}, \mathrm{S}$, ou A predominante, sendo possível abranger as relações entre essas dimensões. Por exemplo, quando apresentamos que a maior parte das espécies de bactérias não são consideradas patogênicas para os seres humanos (TORTORA; FUNKE; CASE, 2010), ou, ainda, quando discutimos as interações entre a flora gastrintestinal humana e as condições ambientais (TASNIM et al., 2017), podemos abranger as relações entre esses quatro domínios. O modelo de saúde adotado como fundamento para a prática pedagógica influenciará a abrangência dos conteúdos nesses diferentes domínios, bem como as diferentes dimensões da saúde (econômica, cultural, ambiental, biológica, histórica, etc.) a serem consideradas, como veremos a seguir.

\section{Abordagem do tema Resistência Bacteriana a Antibióticos a partir de diferentes modelos de saúde}

Para a abordagem do tema da Resistência Bacteriana a Antibióticos, como uma QSC, utilizamos um caso fictício e algumas questões norteadoras das discussões (Quadro 1), sendo estes já utilizados em outros contextos educativos (CONRADO et al., 2011; CONRADO, 2013; 2017; CONRADO; NUNES-NETO; EL-HANI, 2019; 2020). A seguir, indicamos como esse tema poderia ser discutido tendo como fundamento diferentes concepções de saúde. Vale ressaltar que tanto o modelo biomédico quanto o socioecológico de saúde consideram o mau uso dos antibióticos como um problema de saúde pública (CONRADO, 2017).

Quadro 1 - Caso e questões para discussão sobre a QSC “Resistência Bacteriana a Antibióticos"

\begin{tabular}{|c|c|}
\hline Caso: Dilema da mãe preocupada & Questões para discussão \\
\hline $\begin{array}{l}\text { Suponha que você é um(a) pediatra e está } \\
\text { atendendo a mãe de uma criança que está } \\
\text { bastante angustiada com uma doença que } \\
\text { atingiu seu filho. Você sabe que são necessários } \\
\text { exames para determinar com precisão qual a } \\
\text { doença. A mãe pede, contudo, que você receite } \\
\text { antibióticos para o filho porque a criança está } \\
\text { chateada e sentindo muita fraqueza. Você } \\
\text { imagina que há chances de a doença ser } \\
\text { bacteriana. }\end{array}$ & $\begin{array}{l}\text { a) O que você faria: receitaria um antibiótico ou diria } \\
\text { à mãe que será preciso fazer mais exames para saber } \\
\text { se o antibiótico é realmente necessário? } \\
\text { b) Explique as razões que levaram você a tomar tal } \\
\text { decisão. } \\
\text { c) Avalie os riscos e benefícios da decisão que você } \\
\text { tomou. } \\
\text { d) Que conhecimentos científicos, técnicas, } \\
\text { tecnologias e condicionantes sociais e ambientais } \\
\text { você considerou em sua decisão? }\end{array}$ \\
\hline
\end{tabular}

Fonte: Adaptado de Conrado (2013, p.99).

\section{Modelo Biomédico:}

Considerando esse modelo no ensino de ciências, o enfoque sobre essa QSC seria predominantemente sob aspectos biológicos do corpo, princípios anátomo-fisiológicos e químicos, além do desenvolvimento de novos antibióticos (CARVALHO et al., 2008; MARTINS et al., 2015). 
No Quadro 2 abaixo, indicamos algumas informações que podem ser discutidas para subsidiar uma tomada de decisão em relação ao caso e sua principal área de abrangência considerando os domínios CTSA.

Quadro 2 - Alguns conteúdos que podem ser mobilizados a partir da discussão de uma QSC sobre resistência bacteriana a antibióticos, considerando o modelo biomédico

\begin{tabular}{|c|l|}
\hline Domínio & \multicolumn{1}{|c|}{ Informação que sustenta uma tomada de decisão } \\
\hline Ciência & Microrganismos patogênicos podem causar infecção e doenças \\
\hline Ciência & $\begin{array}{l}\text { Bactérias e toxinas aumentam secreções na mucosa do intestino delgado e } \\
\text { aceleram a passagem dos alimentos }\end{array}$ \\
\hline Ciência & $\begin{array}{l}\text { Conhecimentos sobre mutação, variabilidade genética, farmacocinética e } \\
\text { farmacodinâmica }\end{array}$ \\
\hline Ciência & $\begin{array}{l}\text { Controle de sinais e sintomas pode ser feito a partir de outros medicamentos, como } \\
\text { pastilhas anti-inflamatórias }\end{array}$ \\
\hline Ciência & Conhecimentos sobre principais sítios de ação dos antibióticos \\
\hline Tecnologia & $\begin{array}{l}\text { Técnicas e métodos para identificação de microrganismos para a prescrição de um } \\
\text { tratamento adequado }\end{array}$ \\
\hline Tecnologia & $\begin{array}{l}\text { Aparelhos que melhoram a precisão e a velocidade do diagnóstico, a partir dos } \\
\text { sinais e sintomas }\end{array}$ \\
\hline
\end{tabular}

Fonte: Elaborado pelos autores, com base em Conrado (2017).

Podemos perceber que a discussão de uma QSC, com base nesse modelo, permite pouca associação entre os domínios CTSA, uma vez que os fatores biológicos são aqueles assumidos para a saúde do indivíduo. Em outras palavras, este modelo foca nas dimensões orgânicas individuais, dificultando o reconhecimento dos diferentes fatores relacionados aos processos de saúde e doença, como: culturais, econômicos, sociais e ambientais (MARTINS, 2016). Contudo, podemos perceber o grande valor dos conhecimentos científicos e tecnológicos, quando estes estão sobretudo associados à prática cotidiana; quando o sujeito consegue mobilizar esse conhecimento em suas decisões e ações, de modo a obter maior coerência na justificação de ações com base no conhecimento, entendendo a importância da Ciência e da Tecnologia na Sociedade (MORALES, 2018; HODSON, 2018; BEARZI, 2009).

\section{Modelo Socioecológico:}

A partir desse modelo, além de discussões sobre fisiologia humana, química e reprodução bacteriana, outras áreas do conhecimento poderiam ser mobilizadas, como ecologia, evolução, economia, filosofia, política, ética, como pode ser visualizado nos exemplos apresentados no Quadro 3.

Quadro 3 - Alguns conteúdos que podem ser mobilizados a partir da discussão de uma QSC sobre resistência bacteriana a antibióticos, considerando o modelo socioecológico.

\begin{tabular}{|c|l|}
\hline Domínio & \multicolumn{1}{|c|}{ Informação que apoia uma tomada de decisão } \\
\hline Ciência & $\begin{array}{l}\text { Conhecimentos sobre reprodução bacteriana, teoria darwinista da evolução, } \\
\text { seleção natural, coevolução, interações interespecíficas }\end{array}$ \\
\hline Tecnologia & Técnicas e tecnologias para descontaminar ambientes \\
\hline Sociedade & Bactérias resistentes podem contaminar indivíduos saudáveis \\
\hline Sociedade & $\begin{array}{l}\text { Antibióticos são utilizados para fins profiláticos em animais de criação, que são } \\
\text { consumidos por humanos }\end{array}$ \\
\hline Sociedade & $\begin{array}{l}\text { Ações que envolvem pesquisa, produção, prescrição e consumo de antibióticos } \\
\text { são passíveis de análise da ética }\end{array}$ \\
\hline
\end{tabular}




\begin{tabular}{|c|l|}
\hline Sociedade & $\begin{array}{l}\text { Grande pressão e divulgação da indústria farmacêutica para prescrição e consumo } \\
\text { de medicamentos, incluindo os antibióticos }\end{array}$ \\
\hline Sociedade & $\begin{array}{l}\text { Indústria farmacêutica valoriza mais o lucro com a exploração de medicamentos } \\
\text { do que o bem-estar socioambiental }\end{array}$ \\
\hline Sociedade & $\begin{array}{l}\text { Há legislação sobre o uso e o descarte adequados de antibióticos, como: } \\
\text { Resolução RDC no20, de } 5 \text { de maio de 2011. Resolução RDC no 306, de 7 de } \\
\text { dezembro de 2004. Resolução CONAMA no 358/2005. }\end{array}$ \\
\hline Ambiente & $\begin{array}{l}\text { Presença de bactérias resistentes em animais silvestres/selvagens e em diferentes } \\
\text { ambientes aquáticos }\end{array}$ \\
\hline Ciência e Sociedade & $\begin{array}{l}\text { Conhecimentos e práticas para reforçar o sistema imunológico, a partir de contato } \\
\text { com diversos ambientes e animais, redução do estresse e aumento de interações } \\
\text { sociais }\end{array}$ \\
\hline Sociedade e & $\begin{array}{l}\text { Plantas medicinais com ação antibiótica são investigadas pela ciência e podem ser } \\
\text { usadas como antibióticos naturais }\end{array}$ \\
\hline Ambiente & Resíduos de produção e consumo dos antibióticos contaminam cursos d'água \\
\hline
\end{tabular}

Fonte: Elaborado pelos autores, com base em Conrado (2017).

Utilizando esse modelo como base para a educação em saúde, podem ser discutidos interesses políticos e econômicos que influenciam a ciência e a tecnologia, além de impactos ambientais relacionados ao aumento do uso de antibióticos. Com o questionamento sobre os limites da ciência e da tecnologia, aliado a uma reflexão sobre decisões individuais e coletivas, visando o bem comum das próximas gerações humanas e de outros seres vivos (BENCZE et al., 2019), pode-se reduzir o mito do salvacionismo tecnológico, que comumente encontramos no discurso docente e discente, como discutido no trabalho de Rosa e Auler (2016). Ou, ainda, perceber que o discurso científico moderno hegemônico muitas vezes silencia contradições, além de desvalorizar outras formas de conhecimento e prática sobre saúde (RODRIGUES; VON LINSINGEN; CASSIANI, 2019).

Adicionalmente, na discussão de uma QSC sobre resistência bacteriana a antibióticos, consideramos que a adoção do modelo socioecológico de saúde permite o alcance de um maior letramento científico crítico (HODSON, 2011; 2018), pois possibilita: 1) o reconhecimento da influência e das interações entre os elementos que se encontram nas dimensões CTSA; 2) a compreensão de que valores, interesses, e ideologias influenciam informações e atitudes que mantém o status quo (podendo ocultar sujeitos que são prejudicados com decisões para a saúde de apenas parte da população); 3 ) a reflexão sobre a consideração moral e o valor daqueles envolvidos com a QSC, de modo a emitir juízo de valor e tomar posicionamento ético; 4) a tomada de decisão sobre a QSC, e a implementação de ações em direção a uma maior justiça social e sustentabilidade ambiental (CONRADO, 2017).

Nesse sentido, podemos perceber que o modelo socioecológico, por ser mais abrangente, permite discutir questões relacionadas com a interação entre os domínios CTSA, sendo, então, mais adequado para a formação de cidadãos numa perspectiva da educação CTSA. Além disso, diferentes dimensões são consideradas, potencializando reflexões sobre os diversos modos de pensar e agir sobre a saúde, como foi relatado em Conrado; Nunes-Neto; El-Hani (2020), em uma experiência com licenciandos em biologia. Nesse sentido, a promoção da saúde pode ser efetivada não apenas a partir de ações individuais para prevenção de doenças, mas, sobretudo com a implementação de ações coletivas para o aumento da qualidade de vida humana e da sustentabilidade ambiental. 
Por fim, uma QSC sobre Resistência Bacteriana a Antibióticos, em que se adota ambos modelos de saúde, no planejamento docente, para o alcance de determinados objetivos educacionais, possibilita uma abordagem interdisciplinar, por permitir mobilizar, por exemplo, conhecimentos de: genética (ex. mutação); biologia celular (ex. reprodução bacteriana; via plasmídeos); microbiologia (ex. interações entre microrganismos no ambiente e no corpo humano); fisiologia humana (ex. sistemas gastrintestinal e imunológico); evolução (ex. pressão de seleção); ética (ex. conhecimentos sobre teorias morais); política (ex. legislação ambiental e modos de fiscalização sobre uso de antibióticos) para a resolução do problema, entre outros (CONRADO, 2017; CONRADO; NUNES-NETO; EL-HANI, 2020).

\section{Considerações finais}

Neste artigo teórico, apresentamos e discutimos como os modelos de saúde podem influenciar a educação em saúde e utilizamos como exemplo uma QSC sobre resistência bacteriana a antibióticos. Além disso, apontamos que o modelo socioecológico permite uma abordagem mais próxima dos objetivos da educação CTSA, por integrar diferentes áreas do conhecimento, potencializando uma formação mais crítica e engajada dos educandos. Contudo, o modelo biomédico não deve ser descartado, pois, apesar de não ser suficiente, a abordagem individual e biológica também é necessária, sempre de acordo com o objetivo educacional pretendido pelo docente. Cabe, então, ao docente a capacidade para inserir, em seu planejamento e em sua prática pedagógica, momentos para uma abordagem mais restrita e outros para uma abordagem mais abrangente, contribuindo para uma formação mais ampla e integral do estudante. Algumas experiências de aplicação de QSC sobre resistência bacteriana indicam os potenciais dessa temática para a aprendizagem de conteúdos na educação científica (CONRADO et al., 2011; CONRADO, 2013; 2017; FRIEDRICHSEN et al., 2016; CONRADO; NUNESNETO; EL-HANI, 2019; 2020).

Nesse sentido, sugerimos que os cursos de formação inicial e continuada de professores relacionados à educação em saúde possam desenvolver planos e ações que incluam discussões sobre os modelos de saúde e a contribuição de cada um deles para a promoção da saúde, buscando, assim, uma educação mais crítica, abrangente e emancipadora, capaz de efetivamente preparar os sujeitos para tomar decisões considerando sua própria saúde e agir para a manutenção de condições que possibilitem a saúde coletiva e ambiental.

\section{Referências}

ADEGOKE, A; FALEYE, A.; STENSTRÖM, T. A. Residual antibiotics, antibiotic resistant superbugs and antibiotic resistance genes in surface water catchments: Public health impact. Physics and Chemistry of the Earth, v.105, p.177-183, 2018.

ANDRADE, M. A. S. et al. Agrotóxicos como questão sociocientífica na Educação CTSA. Revista Eletrônica Mestrado em Educação Ambiental (REMEA), Rio Grande, v. 33, n. 1, p.171-191, jan./abr., 2016. Disponível em <https://periodicos.furg.br/remea/article/view/5378>. Acesso em: 12 nov. 2019. 
BEARZI, G. When swordfish conservation biologists eat swordfish. Conservation Biology, v.23, n.1, p.1-2, 2009.

BENCZE, L. et al. Bloqueios ao engajamento cívico crítico e ativo na/através da Ciência Escolar: Histórias do Campo. / Roadblocks to critical and active civic engagement in/through school science: stories from the field. Revista Educação e Fronteiras On-Line, Dourados/MS, v.9, n.25, p.47-70, 2019.2 Disponível em: <https://ojs.ufgd.edu.br/index.php/educacao/article/view/11010>. Acesso em 12 jun. 2020.

BOORSE, C. Health as a theoretical concept. Philosophy of Science, v. 44, n. 4, p. 542-573, 1977.

BOORSE, C. On the distinction between disease and illness. Philosophy and Public Affairs, v. 5, n. 1, p. 49-68, 1975.

BUNGE, M. Filosofía para médicos. Barcelona: Gedisa, 2012.

BUSS, P. M. Promoção da saúde e qualidade de vida. Ciência e Saúde Coletiva, v. 5, p. 163-177, 2000. Disponível em: <http://www.scielo.br/scielo.php?script=sci arttext\&pid=S141381232000000100014\&lng=en\&nrm=iso >. Acesso em 10 set. 2019.

BUSS, P. M. Uma introdução ao conceito de promoção de saúde. In: CZERESNIA, D.; FREITAS, C. M. (Orgs.). Promoção da saúde: conceitos, reflexões, tendências. Rio de Janeiro: Fiocruz, 2005.

BUSS, P. M.; PELLEGRINI FILHO, A. A saúde e seus determinantes sociais. PHYSIS: Revista de Saúde Coletiva, Rio de Janeiro, v. 17, n. 1, p. 77-93, 2007. Disponível em: <https://www.scielo.br/pdf/physis/v17n1/v17n1a06.pdf>. Acesso em 10 set. 2019.

CARVALHO, G. S. de. Criação de ambientes favoráveis para a promoção de estilos de vida saudáveis. In: PEREIRA, B. O.; CARVALHO, G. S. de. (Ed.). Actividade física, saúde e lazer: a infância e estilos de vida saudáveis. Lisboa: Lidel, 2006. p. 19-37.

CARVALHO, G. S. de. et al. Comparing Health Education approaches in textbooks of sixteen countries. Science Education International, v. 19, n. 2, p. 133-146, 2008.

CARVALHO, G. S. de. et al. Health education approaches in school textbooks of 14 countries: biomedical model versus health promotion. In: Proceedings of the IOSTE International Meeting on Critical Analysis of School Science Textbook, University of Tunis, Tunis, 7-10 February 2007, p. 380-392, 2007.

CARVALHO, G. S. Health Education in Portuguese Schools: The Contribution of Health and Education Sectors. In: TAYLOR, N. et al. (Eds). Health education in context: An International Perspective on Health Education in Schools and Local Communities. Rotterdam, The Netherlands: Sense Publishers, 2012. p. 37-46.

CARVALHO, I. N. et al. Transgênicos, leis e ciência: trazendo a legislação para a sala de aula de biologia. In: CONRADO, D. M.; NUNES-NETO, N. F. (orgs.). Questões sociocientíficas: fundamentos, propostas de ensino e perspectivas para ações sociopolíticas. Salvador: EDUFBA, 2018, p.277-302.

CDC. Centers for Disease Control and Prevention. Antibiotic Resistance from the Farm to the Table. 2015. Disponível em: <https:// www.cdc.gov/foodsafety/challenges/from-farm-to- 
table.html>. (infográfico em https://www.cdc.gov/foodsafety/pdfs/ar-infographic-508c.pdf). Acesso em: 12 dez 2017.

CONRADO, D. M. et al. Construção e validação de ferramenta para investigação das relações entre conhecimento sobre evolução e tomada de decisão socialmente responsável em questões sócio-científicas. In: ENCONTRO NACIONAL DE PESQUISA EM EDUCAÇÃO EM CIÊNCIAS, 8, 2011, Campinas. Atas [...], Campinas: UNICAMP, 2011, p.1-14.

CONRADO, D. M. Questões Sociocientíficas na Educação CTSA: contribuições de um modelo teórico para o letramento científico crítico. 2017. 237p. Tese (Doutorado em Ensino, Filosofia e História das Ciências) - Instituto de Física, Universidade Federal da Bahia/ Universidade Estadual de Feira de Santana, Salvador, 2017.

CONRADO, D. M. Uso de conhecimentos evolutivo e ético na tomada de decisão por estudantes de biologia. 2013. 220p. Tese (Doutorado em Ecologia) - Instituto de Biologia, Universidade Federal da Bahia, Salvador, 2013.

CONRADO, D. M.; NUNES-NETO, N. F. Questões sociocientíficas para a aprendizagem de conteúdos conceituais, procedimentais e atitudinais no ensino de ciências. In: CONRADO, D. M.; NUNES-NETO, N. F. (Orgs.). Questões sociocientíficas: fundamentos, propostas de ensino e perspectivas para ações sociopolíticas. Salvador: EDUFBA, 2018, p.77-118. Disponível em: < http://repositorio.ufba.br/ri/handle/ri/27202>. Acesso em 12 jun. 2019.

CONRADO, D. M.; NUNES-NETO, N.; EL-HANI, C. Como abordar questões sociocientíficas na sala de aula? A estratégia de cinco fases para o ensino de ciências. Indagatio Didactica, v. 11, p. 915928, 2019. Disponível em <https://proa.ua.pt/index.php/id/article/view/6856>. Acesso em: 10 jan. 2020.

CONRADO, D. M.; NUNES-NETO, N.; EL-HANI, C. N. Dimensões dos conteúdos mobilizados por estudantes de biologia na argumentação sobre antibióticos e saúde. Educação e Pesquisa, São Paulo, v. 46, e223593, p.1-22, 2020. Disponível em <https://www.scielo.br/ pdf/ep/v46/15179702-ep-46-e223593.pdf>. Acesso em: 10 dez. 2020.

CYRINO, E. G. et al. Há pesquisa sobre ensino na saúde no Brasil? Arquivos Brasileiros de Ciências da Saúde (ABCS Health Sciences). v.40, n.3, p.146-155, 2015.

DE SALAZAR, L. Feasibility for Health Promotion under various Decision-Making contexts. 353365. In: MCQUEEN, D. V.; JONES, C. M. (Eds.). Global perspectives on health promotion effectiveness. New York: Springer, 2007.

EKBORG, M.; IDELAND, M.; MALMBERG, C. Science for life - a conceptual framework for construction and analysis of socio-scientific cases. Nordina: Nordic Studies in Science Education, v.5, n.21, p.35-46, 2009.

EMMEL, R. et al. Concepções de saúde e educação para a saúde nos currículos da licenciatura e bacharelado em Ciências Biológicas. Ensino de Ciências e Tecnologia em Revista, v. 8, n. 1, p. 90-97, 2018. Disponível em: <http://srvapp2s.urisan.tche.br/seer/index.php/encitec/ article/view/1677/1223>. Acesso em 12 out. 2019. 
EWLES, L.; SIMNETT, I. Promotion Health - a practical guide. 5. ed. London: Baillière Tindall, 2003.

FENSHAM, P. J. Preparing citizens for a complex world: the grand challenge of teaching socioscientific issues in science education. In: ZEYER, A.; KYBURZ-GRABER, R. (eds.) Science, Environment, Health: Towards a Renewed Pedagogy for Science Education. Springer, Dordrecht; New York, 2012, p.7-29.

FERREIRA, R. L.; DIONOR, G. A.; MARTINS, L. Educação em saúde: é possível adentrar a escola? Candombá - Revista Virtual, v. 9, p. 44-56, 2013. Disponível em <http://revistas.unijorge.edu.br/ candomba/2013-v9n1/pdf/5 ReynanLealFerreira 2013v9n1.pdf>. Acesso em: 10 nov. 2019.

FRIEDRICHSEN, P. J. et al. Design of a socio-scientific issue curriculum unit: antibiotic resistance, natural selection, and modeling. International journal of designs for learning, v. 7, n. 1, p. 1-18, 2016.

GAVIDIA, V.; TALAVERA, M. La construcción del concepto de salud. Didáctica de las Ciencias Experimentales y Sociales (Argentina), n. 26, p. 161-175, 2012.

HODSON, D. Looking to the Future: Building a Curriculum for Social Activism. Auckland: Sense, 2011.

HODSON, D. Realçando o papel da ética e da política na educação científica: algumas considerações teóricas e práticas sobre questões sociocientíficas. In: CONRADO, D. M.; NUNESNETO, N. F. (Orgs.). Questões sociocientíficas: fundamentos, propostas de ensino e perspectivas para ações sociopolíticas. Salvador: EDUFBA, 2018, p.27-57. Disponível em: < http://repositorio.ufba.br/ri/handle/ri/27202>. Acesso em 02 fev. 2020.

KIRBIS, A.; KRIZMANA, M. Spread of antibiotic resistant bacteria from food of animal origin to humans and vice versa. Procedia Food Science, n.5, p.148-151, 2015.

KYBURZ-GRABER, R. Socio-scientific Views on Environment and Health as Challenges to Science Education. In: ZEYER, A.; KYBURZ-GRABER, R. (eds.) Science, Environment, Health: Towards a Renewed Pedagogy for Science Education. Springer, Dordrecht; New York, p.31-48, 2012.

LEE, Y. C. Socio-Scientific Issues in Health Contexts: Treading a rugged terrain. International Journal of Science Education. v.34, n.3, p.459-483, 2012.

LI, A. M. L. Ecological determinants of health: food and environment on human health. Environmental Science and Pollution Research, v.24, n.10, p. 9002-9015, 2015.

MARSHALL, B. M.; LEVY, S. B. Food Animals and Antimicrobials: Impacts on Human Health. Clinical Microbiology Reviews, v.24, n.4, p.718-733, 2011.

MARTíNEZ PÉREZ, L. F.; PARGA LOZANO, D. L. La emergencia de las cuestiones sociocientíficas en el enfoque CTSA Góndola, Enseñanza y Aprendizaje de las Ciencias, v.8, n.1, p.23-35, 2013. Disponível em: <https://revistas.udistrital.edu.co/index.php/GDLA/article/view/5021/6652>. Acesso em 12 set. 2019. 
MARTÍNEZ PÉREZ, L. F.; VILLAMIZAR FÚQUENE, D. P. Unidades didácticas sobre cuestiones socio científicas: construcciones entre la escuela y la universidad. Bogotá: Colciencias; Alternaciencias; Universidad Pedagógica Nacional, 2014.

MARTINS, L. Abordagens da saúde em livros didáticos de Biologia: análise crítica e proposta de mudança. 2016. 158f. Tese (Doutorado em Ensino, Filosofia e História das Ciências) Universidade Federal da Bahia, Salvador, 2016.

MARTINS, L. et al. Dengue, zika e febre chikungunya: a abordagem socioecológica de saúde a partir de uma questão sociocientífica. Revista da SBEnBio, n. 9, p.3845-3856, 2016.

MARTINS, L. et al. Doença de chagas a partir de questões sociocientíficas na educação em saúde. In: CONRADO, D. M.; NUNES-NETO, N. F. (Orgs.). Questões sociocientíficas: fundamentos, propostas de ensino e perspectivas para ações sociopolíticas. Salvador: EDUFBA, 2018, p.213230.

MARTINS, L. et al. Health Education with Socioscientific Issues. In: Programme 11th biannual Conference of the European Science Education Research Association (ESERA) (p.1-4.). Helsink, Finland: Programme, 2015.

MARTINS, L. Saúde no contexto educacional: as abordagens de saúde em um livro didático de biologia do ensino médio largamente usado. 2011. 173f. Dissertação (Mestrado em Ensino, Filosofia e História das Ciências) - Universidade Federal da Bahia, Salvador, 2011.

MARTINS, L.; CASTRO, T. A. Abordagens de saúde em um livro didático de biologia largamente utilizado no ensino médio brasileiro. In: ENCONTRO DE PESQUISA EM EDUCAÇÃO EM CIÊNCIAS, 7., 2009, Florianópolis. Atas [...] Belo Horizonte: ABRAPEC, 2009.

MARTINS, L.; EL-HANI, C. N.; CARVALHO, G. S. A saúde nos livros didáticos de biologia: que ensino propomos? In: BOFF, E. T. de O; CARVALHO, G. S. de; PANSERA-DE-ARAÚJO, M. C. (Orgs.). Interações entre conhecimentos, valores e práticas na educação em saúde. Ijuí - Rio Grande do Sul: UNIJUÍ, 2016, v. 1, p. 133-156.

MARTINS, L. et al. Abordagens da saúde em livros didáticos brasileiros do Ensino Médio. In: ENCONTRO NACIONAL DE PESQUISA EM EDUCAÇÃO EM CIÊNCIAS, 11., 2017, Florianópolis, Atas [...]. Belo Horizonte: ABRAPEC, 2017.

MARTINS, L. et al. Aedes aegypti e questões sociocientíficas para uma abordagem socioecológica de saúde. In: CEBREIROS, M.I.; MEMBIELA, P.; CASADO, N.; VIDAL, M. (Orgs.). La práctica docente en la enseñanza de las ciencias. Ourense: Educación Editora, 2017, v. 1, p. 375-379.

MARTINS, L.; SANTOS, G. S.; EL-HANI, C. Abordagens de saúde em um livro didático de biologia largamente utilizado no ensino médio brasileiro. Investigações em Ensino de Ciências, v.17, n.1, p. 249-283, 2012. Disponível em <https://www.if.ufrgs.br/cref/ojs/index.php/ienci/article/view/215>. Acesso em: 19 nov. 2019. MORALES, A. P. O conhecimento social da ciência empodera os cidadãos. Ciência e Cultura, São Paulo, v. 70, n. 1, p. 14-19, 2018. Disponível em: <http://cienciaecultura.bvs.br/ scielo.php?script=sci arttext\&pid=S0009-67252018000100006\&lng=en\&nrm=iso >. Acesso em 10 set. 2019. 
MYERS, S. S. et al. Human health impacts of ecosystem alteration. Proceedings of the National Academy of Sciences of the United States of America. v.110, n.47, p.18753-18760. 2013.

NAIDOO, J.; WILLS, J. Fondations for health promotion. 3. ed. London: Baillière Tindall, 2009.

NUTBEAM, D. Health literacy as a public health goal: a challenge for contemporary health education and communication strategies into the 21st century. Health Promotion International, v.15, n.3, p.259-267. Oxford University Press, 2000.

NUTBEAM, D. La promoción de la salud en acción: ideas prácticas para llenar a cabo los programas. Salud, supl., feb., 1988.

ODA, W. Y. Concepções de saúde entre docentes de biologia: um instrumento investigativo. Amazônia: Revista de educação em ciências e matemáticas, v.8, n.16, p.99-109, 2012. Disponível em: <https://periodicos.ufpa.br/index.php/revistaamazonia/article/view/1662/2073>. Acesso em 25 ago. 2019.

POWER, M.; EMERY, S.; GILLINGS, M. Into the Wild: Dissemination of Antibiotic Resistance Determinants via a Species Recovery Program. PLoS ONE, n.8, v.5, e63017, p.1-5, 2013.

QUEIROZ, E. L. S.; CONRADO, D. M.; SILVA, E. L. Relações CTSA em discussões de licenciandos de Biologia sobre uma Questão Sociocientífica. Indagatio Didactica, v.11, p.463-479, 2019. Disponível em <https://proa.ua.pt/index.php/id/article/view/6205>. Acesso em: 02 fev. 2020.

RATCLIFFE, M.; GRACE, M. Science education for citizenship: teaching socio-scientific issues. Maidenhead, UK: Open University Press, 2003.

RODRIGUES, V. A. B.; VON LINSINGEN, I.; CASSIANI, S. Formação cidadã na educação científica e tecnológica: olhares críticos e decoloniais para as abordagens CTS. Revista Educação e Fronteiras On-Line, Dourados/MS, v.9, n.25, p.71-91, 2019. Disponível em: <https://ojs.ufgd.edu.br/index.php/educacao/article/view/11012>. Acesso em 12 jun. 2020.

ROSA, S. E.; AULER, D. Não neutralidade da ciência-tecnologia: problematizando silenciamentos em práticas educativas CTS. Alexandria: Revista de Educação em Ciência e Tecnologia, Florianópolis, v.9, n.2, p.203-231, 2016. Disponível em: <https://periodicos.ufsc.br/index.php/alexandria/article/view/1982-5153.2016v9n2p203>.

Acesso em 28 ago. 2019.

SANTOS, F. M. S. et al. Medicalização da vida e análise do comportamento a partir de questões sociocientíficas. In: CONRADO, D. M.; NUNES-NETO, N. F. (Orgs.). Questões sociocientíficas: fundamentos, propostas de ensino e perspectivas para ações sociopolíticas. Salvador: EDUFBA, 2018, p.245-260.

SANTOS, W. L. P. Educação CTS e cidadania: confluências e diferenças. Amazônia: Revista de educação em ciências e matemáticas, v.9, n.17, p.49-62, 2012. Disponível em: $<$ https://periodicos.ufpa.br/index.php/revistaamazonia/article/view/1647/2077>. Acesso em 19 fev. 2020.

SANTOS; J. C.; CONRADO, D. M.; NUNES-NETO, N. Poluição hídrica: uma questão sociocientífica para abordar ética ambiental no ensino fundamental de ciências. In: CONRADO, D. M.; NUNES- 
NETO, N. F. (Orgs.). Questões sociocientíficas: fundamentos, propostas de ensino e perspectivas para ações sociopolíticas. Salvador: EDUFBA, 2018, p.191-2012.

SARMENTO, A. C. H. et al. Princípios de design para um ensino de Ciências contextualizado pelas relações entre ciência-tecnologia-sociedade-ambiente. Revista Educação e Fronteiras On-Line, v. 9, p. 183-207, 2019. Disponível em <https://ojs.ufgd.edu.br/index.php/educacao/article/view/11101 >. Acesso em: 02 fev. 2020.

SEGRE, M.; FERRAZ, F.C. O conceito de saúde. Revista de Saúde Pública, v.31, n.5, p. 538-542, 1997. Disponível em: <http://www.scielo.br/scielo.php?script=sci arttext\&pid=S003489101997000600016\&lng=en\&nrm=iso >. Acesso em 08 set. 2019.

SILVA, S. M. B. Doping genético: uma questão sociocientífica para o ensino superior. In: CONRADO, D. M.; NUNES-NETO, N. F. (Orgs.). Questões sociocientíficas: fundamentos, propostas de ensino e perspectivas para ações sociopolíticas. Salvador: EDUFBA, 2018, p.261276.

TACCONELLI, E. et al. Discovery, research, and development of new antibiotics: the WHO priority list of antibiotic-resistant bacteria and tuberculosis. The Lancet Infectious Diseases. v.18, n.3, p.318-327, 2018.

TASNIM, N. et. al. Linking the Gut Microbial Ecosystem with the Environment: Does Gut Health Depend on Where We Live? Frontiers in Microbiology. v.8, p.1-8, 2017.

TORTORA, G. J.; FUNKE, B. R; CASE, C. L. Microbiology: an introduction. 10. ed. San Francisco: Benjamin Cummings, 2010.

VALADÃO, M. M. Saúde na escola: um campo em busca de espaço na agenda intersetorial. 2004. 154 f. Tese (Doutorado em Serviços de Saúde) - Departamento de Prática de saúde Pública, Universidade de São Paulo, São Paulo, 2004.

ZEIDLER, D. et al. Beyond STS: A Research-based Framework for Socioscientific Issues Education. Science Education, n.89, p.357-377, 2005.

ZEYER, A.; DILLON, J. Science | Environment | Health. Towards a reconceptualization of three critical and inter-linked areas of education. International Journal of Science Education. v.36, n.9, p.1409-1411, 2014. 